\title{
The Maastricht Criteria and the Euro: Has the Convergence Continued?
}

\author{
Wolfgang Polasek \\ Institute of Advanced Studies \\ Christian Amplatz \\ Free University of Bozen-Bolzano
}

\begin{abstract}
We analyze the performance of the Maastricht convergence criteria (inflation, long-term interest rate, annual and overall public debt to GDP) of the European Monetary Union (EMU) that led to the introduction of the Euro on Jan. $1^{\text {st }} 1999$ as book currency. For our analysis we define 3 regimes: a) the Maastricht regime from 1992-97 starting from the year when the EMU was established, b) the Amsterdam regime 1997-1999 which is based on the Pact of Stability and Growth (PSG), decided by the EU in 1997 in Amsterdam and c) the Euroland regime 2000-2001, after the introduction of the Euro as book currency. The convergence process is analysed with respect to these 3 regimes, and we test also for a smooth or a rough transition between these 3 regimes. Given the regimes, we test the convergence in econometric models to see if the first and second moments of the convergence process are time dependent. Furthermore we can check if there was a smooth transition process between the regimes and if the convergence process has stabilized around a target path. We find that the speed of the convergence processes for the monetary authority controlled variables inflation and interest rates was rather impressive and very different from the government controlled variables annual deficit and the public debt.
\end{abstract}

\footnotetext{
*Corresponding address: Dr. Wolfgang Polasek, Institute of Advanced Studies Vienna, Stumpergasse 56, A-1060 Wien, Austria, E-mail: polasek@ihs.ac.at (C)2003-Center for International Economics, Sejong Institution, All Rights Reserved.
} 


\section{- JEL Classifications: C2, E1}

- Key words: EMU convergence, Maastricht criteria, Heteroskedastic spline models, ARCH regime shifts, Inflation, Public deficits, Interest rates and public debt

\section{Introduction}

The EMU consists presently of 12 member states, together with Greece, which joined the Eurozone in 2001, two years after the start of new currency in 1999. The performance of the EMU countries according to the Maastricht criteria for the years before and after the formal launch of the Euro on Jan. $1^{\text {st }} 1999$ is an important threshold for a common European economic policy. With the planned enlargement of the EU new candidates for Euro-Land will have to follow the Maastricht criteria as well. Clearly, the compliance of these prescriptions of the Pact on Stability and Growth (PSG: due to 1997) and the various discussions of these criteria are a highly political issue and is important for the future stability of the euro. Therefore the analysis of the economic convergence process is an important issue and it will serve as a benchmark for future discussion for the performance of countries in Euro-Land. We will adopt an econometric view of the economic convergence process and we will analyse the joint time series behaviour of the 4 crucial economic indicators (inflation, public deficits, interest rates and public debt) over the time period 1992-2001.

We will consider two models for the modelling of the convergence behaviour over the period 1992-2001: a 2-regime and a 3-regime model. Also we will consider a smooth spline model and a piecewise regression model where the pieces might be not connected. The spline model preserves continuity at the break point while the piecewise regression model describes the trend lines independently in two or 3 regimes.

The description of the convergence process is a simple time trend model that could have possibly quite different trends in the consecutive regimes. The 3regime model introduces a second break point at the end of 1999 to describe the performance for the last two years. We will test the convergence for the spline and the piecewise linear regression model. Also we distinguish the following types of convergence processes:

a) Simple mean convergence: The cross-sectional means of the time series are 
decreasing.

b) Targeted mean convergence: The cross-sectional means of the time series are decreasing to a target level and the cross-sectional variance of the process is also decreasing.

c) Simple variance convergence: The cross-sectional variances of the time series are decreasing.

Simple mean (or variance) divergence: The cross-sectional means (or variances) of the time series are increasing.

\section{A. Modelling Goals and Caveats}

Clearly, our approach is merely an ex-post statistical measurement of the observed movement in the underlying time series for the Maastricht Criteria of the EU countries. Since no behavioral assumptions are present in our econometric models, we concentrate and describe the phenomenon of convergence in a statistical sense. A driving role for the convergence process are expectations and policy credibility which are rather complicated to impose in a descriptive approach and therefore they are not considered explicitly in this paper.

Economically we expect from the results, that modelling the convergence process for inflation and long-term interest rates on the one side and annual deficits on the other side can be quite different. While the criteria for inflation and long-term interest rates were considered to be a strict entrance benchmark for the EMU, the criterion on government finances was less restrictive. Governments who had the intention to meet the government finance criteria were considered to be also eligible for Euroland.

We expect that inflation and interest rates, two of the convergence criteria, have similar convergence behavior because of their close economic interrelationship. Indeed, for several models inflation depends on the exogenously given level of nominal interest rates (e.g. see Dornbusch 1976). On the other hand Central Banks, especially the ECB (see Treaty on EU (1999), articles 105-124), set the level of nominal interest rates according to inflationary pressure. Moreover, debt ratios and annual deficits are also interrelated. On the other hand convergence performance of these two groups of criteria is not necessarily related to each other, especially not in the beginning of the convergence procedure, i.e. in our notation for the Maastricht regime. The reason is that fiscal convergence is driven by business cycles and fiscal discipline.

Though, fiscal discipline has certainly improved in the Eurozone by the PSG. 
Unfortunately, the problem of business cycles affecting government budgets was not taken into account by the PSG, since it focuses on annual deficits instead of business cycle independent structural deficits. This shows some weaknesses about the two fiscal Maastricht criteria and the PSG. Thus there is possibly room for improving rules of the PSG in the future.

Further, we argue that the PSG is not necessarily satisfactory, neither for guaranteeing stabilization of achieved convergence of interest rates and inflation nor for implementing a consistent long-term trend towards perfect convergence of Maastricht criteria nor for necessarily achieving economic convergence. The reason is that the PSG may create incentives for fiscal discipline and thus for fiscal convergence, but does not necessarily imply neither economic convergence (e.g. in the sense of similar income levels or growth rates) nor convergence in the sense of converging interest rates and inflation.

Still concerning the PSG, we conclude that there is a principal-agency problem. Indeed, member countries have fewer incentives for further improving or at least stabilizing convergence, once they joined the Euro. Thus there is some evidence for divergence in the Euroland regime for some criteria. This is consistent with the hypothesis that the concept of convergence is highly time dependent. In fact we conclude that different time periods may show totally different convergence performance.

Greece is treated as a special case in this paper because of its different economic stage compared to other EMU members. Analysis without Greece deals with the fact of being an outlier, but on the same time it allows classifying the convergence performance of Greece, when comparing to results including Greece. In this sense Greece is somewhat like a pioneer for the coming eastern enlargement. Once the "eastern enlargement" of the EU has taken place, discussion about the adoption of the Euro in those new member countries will arise.

Furthermore we are interested in the question if the convergence process in the first moments (i.e. the mean equation of the spline model) was accompanied by a convergence process in the $2^{\text {nd }}$ moments. This means that we fit a heteroskedastic 2- or 3-regime convergence model for the conditional variances of the piecewise regression models.

Thus, it is not surprising that after the introduction of the Euro not all countries fulfil the restriction of the maximum $60 \%$ debt to GDP ratio: 5 and 6 countries are not able do so in 2000 and 2001. We will see that the convergence for inflation and interest rates, - these are the two criteria depending on efficient financial and 
goods and services markets - already took place in the first regime before 1997. This is a clear indication that real economic convergence can be achieved quicker than fiscal discipline for the public sector.

Also, we want to emphasize that the proposed convergence model is motivated by the econometric technique of spline models and has nothing to do with the approaches to economic convergence as in Barro et al. (1995) or Ben-David (1993). Different ideas to economic convergence by index construction can be found in Hobijn and Franses (2000, 2001).

The plan of the paper is as follows: We start in section 1 with an introduction into the modelling process and the data base and the Maastricht criteria are described in section 2 . In section 3 we outline briefly our econometric convergence approach while in section 4 we report the results. Section 5 reports the results on the heteroskedastic convergence models. The last section concludes. The appendix summarizes the heteroskedastic convergence models.

\section{The EMU and the Maastricht Criteria}

First, consider a short historical overview of the EMU. The Maastricht treaty laid out three stages to arrange the EMU:

Stage 1, July 1990 - Dec 1993:

- Free movement of capital,

- Narrowing of ERM band,

- Closer co-operation between central banks,

- Closer co-ordination of economic policies.

Stage 2, Jan. 1994 - Dec 1998:

- Convergence of member states' economic and monetary policies,

- Establishment of European Central Bank,

- Independence of national banks,

- Participating countries fix their exchange rates.

Stage 3, Jan. 1999: Introduction of the Euro as a book currency,

Jan. 2002: Launch of euro notes and coins.

In 199811 of the $15 \mathrm{EU}$ member states decided to form the European monetary union (EMU), leaving Denmark, Greece, Sweden and the UK outside the "eurozone".

In January 1999, financial markets of the EMU countries began operating in euros. Two years later, Greece finally met the economic requirements for 
membership and at the Lisbon meeting in June 2000 Greece was allowed to join the euro in January 2001.

\section{A. The Maastricht Criteria}

We consider the twelve countries belonging to the European Monetary Union (EMU): Germany, France, Belgium, Luxembourg, Austria, Finland, Ireland, the Netherlands, Italy, Spain, Portugal are the founding states and Greece joined two years later. The other three EU states, Britain, Denmark, and Sweden have not joined the Euro.

The Maastricht Treaty (1992) contains important macro-economic requirements in order to become a member of Euroland, i.e. to participate in the EMU. The treaty lists 4 types of criteria that are slightly different from the 4 "Maastricht" criteria, which we will use for the analyses of the convergence process. The $3^{\text {rd }}$ point mentioned in the treaty deals with exchange rates, but this was only important before the official launch of the Euro on Jan. $1^{\text {st }} 1999$. Therefore we have not considered exchange rates for the present analysis, and we investigate the behaviour of government budgets according to common practice - by two important time series, the annual deficit and the debt ratio.

\section{Price Stability}

"The achievement of a high degree of price stability [...] will be apparent from a rate of inflation which is close to that of, at most, the three best-performing Member States in terms of price stability."

In practice, the inflation rate of a given member state must not exceed by more than $1 \frac{1}{2}$ percentage points that of the three best-performing member states in terms of price stability during the year preceding the examination of the situation in that member state.

\section{Government Finances}

"The sustainability of the government financial position [...] will be apparent from having achieved a government budgetary position without a deficit that is excessive [...]."

In practice, the Commission, when drawing up its annual recommendation to the Council of Finance Ministers, examines compliance with budgetary discipline on the basis of the following two criteria:

a) The annual government deficit: the ratio of the annual government deficit to 
gross domestic product (GDP) must not exceed 3\% at the end of the preceding financial year. If this is not the case, the ratio must have declined substantially and continuously and reached a level close to $3 \%$ (interpretation in trend terms) or, alternatively, must remain close to $3 \%$ while representing only an exceptional and temporary excess;

b) Government debt: the ratio of gross government debt to GDP must not exceed $60 \%$ at the end of the preceding financial year. If this is not the case, the ratio must have sufficiently diminished and must be approaching the reference value at a satisfactory pace (interpretation in trend terms).

\section{Exchange Rates}

"The observance of the normal fluctuation margins provided for by the exchange-rate mechanism of the European Monetary System, for at least two years, without devaluing against the currency of any other Member State."

This criterion is not relevant for this study, as we only look at performance of countries already being members with a common currency.

\section{Long-term interest rates}

"The durability of convergence achieved by the Member State [...] being reflected in the long-term interest-rate levels."

In practice, the nominal long-term interest rate must not exceed by more than 2 percentage points that of the three best-performing Member States in terms of price stability. Note that this refers to the same Member States as those in the case of the price stability criterion. The crucial period is the year preceding the examination of the Member State for joining the euro.

Therefore we will focus our analysis on the inflation rates, the nominal longterm interest rates, annual government deficits and total public debt of each member, while just ignoring the criterion about exchange rates, as it is obsolete now.

\section{B. The Modelling Strategy}

The empirical strategy employed in the paper implicitly assumes that there is a common (across member states) 'generating mechanism'. The implicit assumption is a common cross-sectional time trend according to Quah (1993). According to this view our modeling proposal considers the fact that the time series do not follow a uniform linear trend, but it could be a broken, segmented, 
possibly piecewise connected ("smooth") trend. For each Maastricht criterion we will estimate a convergence model across the 12 EMU members and results about the convergence performance will be obtained independently for the four variables. We will treat the convergence modelling as a model selection problem: We look for the best performing parsimonious convergence model. Thus, this approach makes many estimates necessary because different piecewise linear regression models have to be compared to each other. Furthermore, we have to cope with outliers, since in particular Greece is a special case for the convergence models. Greek time series can be considered to document a previous unseen catching-up process and therefore it is not surprising that Greek time series are "outliers" in the sense of showing more extreme values in the first years of the convergence process if compared to other countries.

Unfortunately, from an econometric point of view, the Greek time series create a technical difficulty in the assumption that the convergence process in the Maastricht regime stems from a data generating process of the EU countries which is "uniform". That means they agree at the same time at similar economic policy measures, they have the same time horizon to meet their goals, and they have about comparable starting conditions. Therefore the fact that Greece entered the EMU in 2001, after the introduction of the Euro by the other countries, distorts the estimation of the convergence process (due to a single country) and has an "outlier bias" effect on the least squares estimates.

To find out how big this distortion effect on the estimates can be, we will analyze the convergence in our models without Greece (and occasionally without other "outlying" countries) to see its influence on the overall convergence behaviour. Furthermore we will check the analysis of overall public debt for outlying countries. As Luxembourg, Belgium, Italian and Greece all show extreme debt values compared to the other 8 countries (i.e. Luxembourg has a very low one, the other three a very high one), we will estimate the regression model for the group of 8 middle or "core" countries.

\section{The Data Base}

Data for EMU members are taken from Eurostat on a monthly or yearly basis. The inflation rate is calculated from the price index (source: Datastream, IMF) from Sept. 1991 to Sept. 2001. For the interest rates we had to start the convergence analysis in April 1994 since the data were not available or comparable before 1994. The long-term interest rate for each country is the 
"Benchmark Bond 10 yr (DS)".

The monthly time series on the interest rate and the inflation were available up to September 2001. Finally the annual time series on annual deficit to GDP and overall public debt to GDP are based on OECD forecasts for the year 2001, since they are the only annual data sets that are available.

After calculating the mean of the three best performing countries for inflation rates each month, we subtract it from all national inflation rates for comparative purposes. The same procedure is applied for interest rates. Data for annual and overall public debt are all in absolute percentage terms to GDP. They are due to an OECD database for forecasts, annual reports of the European Central Bank for 1998 to 2000 and Eurostat, covering the years from 1990 to 1997. These data sets for the four criteria are sufficient for our research objective.

\section{The Methodology}

To find out whether the convergence process of the Maastricht treaty has not eroded but continued in the two years since the introduction of the Euro we suggest to model the convergence path for the EMU member states over the last decade by a piecewise regression model. By looking at the graphs of the individual time series for the convergence models it is quite evident that there was an important change in the convergence process at the end of 1997. Indeed, there was a European Council meeting in Amsterdam on June 17 $7^{\text {th }}$ 1997, which agreed on the so-called Pact of Stability and Growth (PSG). This political decision made clear that the admittance of countries into Euroland would be based on hard economic facts. The pact enforces also the fulfilment of EMU criteria over the next years. Maybe it was not as important as the Maastricht Treaty (1992) was, but it provided for market participants really strong expectations for convergence to take place. Though, we will show that the convergence for inflation and interest rates of EMU members, which are the two criteria depending on efficient financial and goods \& services markets, already approached a similar level in member countries before, may it partly be for real economic convergence already starting before and for some amount due to expectations of market participants already anticipating real events.

Our convergence modelling is based on a separate and a continuous piecewise linear regression model for a pooled cross-section and time series data set. We first introduce the so-called continuous piecewise regression or spline model (see e.g. 
Pindyck and Rubinfeld, 1998) using dummy variables for the known break point $\mathrm{X}^{*}$ which is assumed at the end of 1997.

The 2-regime spline model is given by

(1) $\mathrm{y}_{\mathrm{t}}=\mathrm{b}_{0}+\mathrm{b}_{1} \mathrm{x}_{\mathrm{t}}+\mathrm{b}_{2}\left(\mathrm{x}_{\mathrm{t}}-\mathrm{x}^{*}\right) \mathrm{D}_{\mathrm{t}}+\mathrm{u}_{\mathrm{t}}, \quad \operatorname{Var}\left(\mathrm{u}_{\mathrm{t}}\right)=\mathrm{s}^{2}$,

where the dummy variable is defined as

(2) $D_{t}=1$ for $x_{t}>x^{*}$ and $D_{t}=0$ else (for $x_{t}<x^{*}$ ).

This leads to the two regression lines before and after the break point $x^{*}$ which has the property that

$$
\begin{array}{ll}
D_{t}=0: y_{t}=b_{0}+b_{1} x_{t}+u_{t}, & \text { for } x_{t}<x^{*}, \\
D_{t}=1: y_{t}=b_{0} *+b_{1} * x_{t}+u_{t}, & \text { for } x_{t}>x^{*},
\end{array}
$$

The coefficients for regime 2 are $b_{0} *=b_{0} b_{2} x^{*}$ and $b_{1} *=b_{1}+b_{2}$.

The 2-regime separate regression model has the form of a regression model with a "multiplicative dummy" variable where we use the regressor $x_{t}-x^{*}$ :

(3) $\mathrm{y}_{\mathrm{t}}=\mathrm{b}_{0}+\mathrm{b}_{1}\left(\mathrm{x}_{\mathrm{t}}-\mathrm{x}^{*}\right)+\mathrm{a}_{0} \mathrm{D}_{\mathrm{t}}+\mathrm{a}_{1}\left(\mathrm{x}_{\mathrm{t}}-\mathrm{x}^{*}\right) \mathrm{D}_{\mathrm{t}}+\mathrm{u}_{\mathrm{t}}$, Var $\left(\mathrm{u}_{\mathrm{t}}\right)=\mathrm{s}^{2}$,

In this model the regressor variable $x_{t}-x^{*}=t-t^{*}$ is the break point adjusted time variable and it shifts the coordinate system into the break point $t^{*}$. Therefore $a_{0}$ and $b_{0}$ are the intercepts of the two independent trends while $a_{1}$ and $b_{1}$ are the slopes of the two regimes. The 2-piece separate regression model (3) is the unrestricted model and it contains the 2-regime spline model (1) as special case. Therefore the hypothesis of a continuous trend can be tested if the coefficient $\mathrm{a}_{0}=$ 0 , i.e. a simple t-test.

The 3-regime separate regression model has the form

(4) $\mathrm{y}_{\mathrm{t}}=\mathrm{b}_{0}+\mathrm{b}_{1}\left(\mathrm{x}_{\mathrm{t}}-\mathrm{x}_{\mathrm{a}}{ }^{*}\right)+\mathrm{a}_{0} \mathrm{D}_{\mathrm{t}}^{\mathrm{a}}+\mathrm{a}_{1}\left(\mathrm{x}_{\mathrm{t}}-\mathrm{x}_{\mathrm{a}}{ }^{*}\right) \mathrm{D}_{\mathrm{t}}^{\mathrm{a}}+\mathrm{c}_{0} \mathrm{D}_{\mathrm{t}}^{\mathrm{c}}+\mathrm{c}_{1}\left(\mathrm{x}_{\mathrm{t}}-\mathrm{x}_{\mathrm{c}}{ }^{*}\right) \mathrm{D}_{\mathrm{t}}^{\mathrm{c}}+\mathrm{u}_{\mathrm{t}}$, $\operatorname{Var}\left(u_{t}\right)=s^{2}$.

$D_{t}^{a}$ is the dummy variable for the regime $A$, i.e. $D_{t}^{a}=1$ for $x_{t}>x_{a}{ }^{*}$ and $D_{t}^{a}=$ 0 else; and $\mathrm{D}_{\mathrm{t}}^{\mathrm{c}}$ is the dummy variable for the regime $\mathrm{C}$, i.e. $\mathrm{D}_{\mathrm{t}}^{\mathrm{c}}=1$ for $\mathrm{x}_{\mathrm{t}}>\mathrm{x}_{\mathrm{c}}{ }^{*}$ and $\mathrm{D}_{\mathrm{t}}^{\mathrm{c}}=0$ else. Now $\mathrm{x}_{\mathrm{a}}{ }^{*}$ is the known break point for the regime $\mathrm{A}$ and $\mathrm{x}_{\mathrm{c}} *$ is the known break point for the regime $\mathrm{C}$.

Scheme 1. The regimes for testing the covergence model

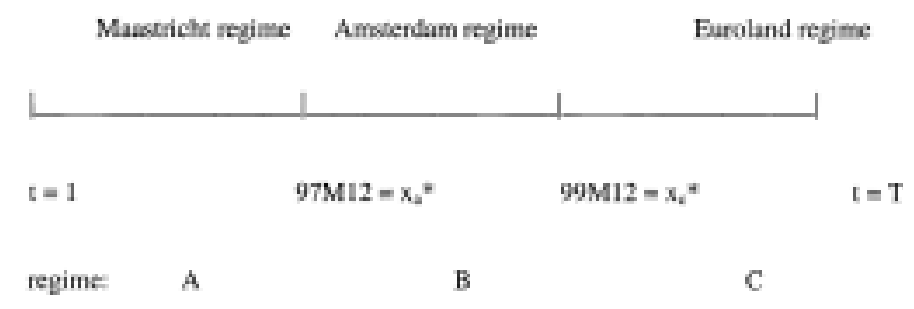


One break point $\mathrm{x}_{\mathrm{a}}{ }^{*}$ is only needed to estimate the two regime model while two break points $\mathrm{x}_{\mathrm{a}} *$ and $\mathrm{x}_{\mathrm{c}} *$ are needed to estimate the 3-regime spline model. The first break point is assumed to be December 1997 as 1997 was the crucial year for the final decision which country was allowed to join the Euro. This decision for the EMU was to be made in the middle of 1998 after 1997 data for the convergence criteria being available. The second break point $\mathrm{x}_{\mathrm{c}} *$ marks the starting point of the Euro as a book currency, and we choose for data compatibility reasons December 1999. We will call the first regime as the "Maastricht regime" and the second regime until the end of 1999 when the Euro was created as the "Amsterdam regime". The third regime is the "Euroland regime".

\section{A. Testing in the Convergence Models}

We will test the following 4 hypotheses for the piecewise regression models (continuous or separate):

Hypothesis 1: The EMU countries have reached convergence in the Maastricht regime.

Then the pooled trend coefficient has to be negative (and the intercepts should be positive). If countries would have no interests in the Maastricht convergence process then on average they would have maintained their old economic policy and the pooled trend coefficient would be zero. This leads to the one-sided hypotheses that the countries have not reached convergence as being the nullhypothesis, and the hypotheses

$\mathrm{H}_{0}: \mathrm{b}_{1}=0$ vs. $\mathrm{H}_{1}: \mathrm{b}_{1}<0$.

Hypothesis 2: The EMU countries have stabilized the convergence process in the Amsterdam regime.

This implies a simple t-test for the slope coefficient in the $2^{\text {nd }}$ regime:

$\mathrm{H}_{0}: \mathrm{b}_{1} *=0$ vs. $\mathrm{H}_{1}: \mathrm{b}_{1} * \neq 0$.

Hypothesis 3: The EMU countries have not diverged in the Euroland regime.

Again, this implies a one-sided t-test for the slope coefficient in the 3rd regime:

$\mathrm{H}_{0}: \mathrm{b}_{1} *=0$ vs. $\mathrm{H}_{1}: \mathrm{b}_{1} *>0$.

In contrast to the separate 3-regime regression model in (4) we can estimate the 3-regime continuous spline model:

(5) $\mathrm{y}_{\mathrm{t}}=\mathrm{b}_{0}+\mathrm{b}_{1}\left(\mathrm{x}_{\mathrm{t}}-\mathrm{x}_{\mathrm{a}}{ }^{*}\right)+\mathrm{a}_{1}\left(\mathrm{x}_{\mathrm{t}}-\mathrm{x}_{\mathrm{a}}{ }^{*}\right) \mathrm{D}_{\mathrm{t}}^{\mathrm{a}}+\mathrm{c}_{1}\left(\mathrm{x}_{\mathrm{t}}-\mathrm{x}_{\mathrm{c}}{ }^{*}\right) \mathrm{D}_{\mathrm{t}}^{\mathrm{c}}+\mathrm{u}_{\mathrm{t}}, \operatorname{Var}\left(\mathrm{u}_{\mathrm{t}}\right)=\mathrm{s}^{2}$,

Therefore we compare the separate 3-regime regression model with the continuous spline model by an F-test on:

Hypothesis 4: The EMU countries have stabilized the convergence in the 
Amsterdam and the Euroland regime in a continuous way (smooth transition).

The compound hypothesis is that the restricted model holds:

$\mathrm{H}_{0}: \mathrm{a}_{0}=0$ and $\mathrm{c}_{0}=0$ vs. $\mathrm{H}_{1}: \mathrm{a}_{0} \neq 0$ or $\mathrm{c}_{0} \neq 0$.

A smooth transition is preferred if the spline model is more likely than the piecewise 3-regime model. Instead of the F-test we can also use a likelihood ratio test or we simply compare the models by information criteria like AIC (Akaike 1973), or the Schwartz criterion. Thus, our approach tries to find stylized facts in the spirit of a critical empirical analysis as proposed by Popper (2000).

Hypothesis 5: The EMU countries have achieved a) convergence also with respect to the variance in the Maastricht regime and b) have not diverged in variance during the Amsterdam and Euroland regime.

Let $\alpha_{\text {time }}, \beta_{\text {time }}$ and $\gamma_{\text {time }}$ be the coefficient of the TIME variable in the variance equation of the 3-regime ARCH regression model (see appendix), then the two hypotheses imply:

a) $\mathrm{H}_{0}: \alpha_{\text {time }}<=0$ vs. $\quad \mathrm{H}_{1}: \alpha_{\text {time }}>0$;

b) $\mathrm{H}_{0}: \beta_{\text {time }}=\gamma_{\text {time }}=0$ vs. $\quad \mathrm{H}_{1}: \beta_{\text {time }}=\gamma_{\text {time }} \neq 0$.

We shall denote a convergence process in a certain regime a "targeted convergence" if the TIME coefficients in both, the mean and the variance equation are significantly different from zero and negative. If the regime dependent TIME coefficients are positive then the process is called in this regime divergent. If the TIME coefficients are not significantly different from zero then there is no convergence (or divergence) for the given partition of the process into regimes.

In the next section we report the main results of the convergence models.

\section{Main Results}

In the following section we compare the estimation results for different convergence models for each Maastricht criterion.

\section{A. Inflation Rates}

The estimates for the 2-regime spline regression that includes all the 12 members are (values within brackets are p-values):

Before 98M1: Infl.differential $=3.175-0.029 *$ Time

(p-value)

$$
\text { (0.0000) (0.0000) }
$$

After 97M12: Infl.differential $=0.773+0.002 *$ Time

(p-value)

(0.0001) (0.0000) 
On average the inflation differential in Euroland with respect to the mean of the three best performing countries decreased from $3.17 \%$ to only $0.96 \%$ at the end of 1997 (about 3 basis points per month). Surprisingly there was no continued convergence in the second Amsterdam regime. Since the regression coefficient is positive there was actually a small divergence, namely 0.2 basis points per month with the inflation rate differential increasing to $1.08 \%$ at the end of the second regime. Regression estimates are all significantly different from 0 ( $\mathrm{p}$-value $=$ 0.0001).

Since Greece data behave like outliers, we have estimated the 2-regime model for 11 EMU countries.

Before 98M1: Infl.differential $=1.960-0.017 *$ Time

$$
\text { (p-value) (0.0000) (0.0000) }
$$

After 97M12: Infl.differential $=-0.047+0.010 *$ Time (p-value)

(0.0000) (0.0000)

The estimates for the 11 countries show a lower pace of convergence (1.7 basis points compared to 2.9 per month) in the first regime. Again we see a divergence of 1 basis point for the second regime which is considerably higher than for the first regime. The differential is $1.96 \%$ for September 1991, $0.68 \%$ for December 1997 and $1.11 \%$ for September 2001.

Next we want to check if the divergence process has continued for the $3^{\text {rd }}$ regime in Euroland between 2000 and 2001 (again without Greece) without Greece:

$$
\begin{array}{lc}
\text { Before 98M1: Infl.differential } & 1.956-0.017 * \text { Time } \\
& (0.000)(0.000) \\
\text { From 98M1 to 99M12: Infl.differential }= & 0.063+.008 * \text { Time } \\
& (0.000)(0.010) \\
\text { After 99M12: Infl.differential } & -0.392+0.013 * \text { Time } \\
& (0.000)(0.7676)
\end{array}
$$

While the slope coefficient in the $3^{\text {rd }}$ regime is not significant, the positive slope in the $2^{\text {nd }}$ regime is. This can be seen as the results of an increased spread in the inflation rates in the Euroland regime. Note, that hypothesis 3, i.e. the divergence of countries during the Euroland regime cannot be confirmed significantly by the $t$ test. 
Figure 1. Inflation differential for the 3-regime spline model (break points at 97M12 and 99M12) without Greece

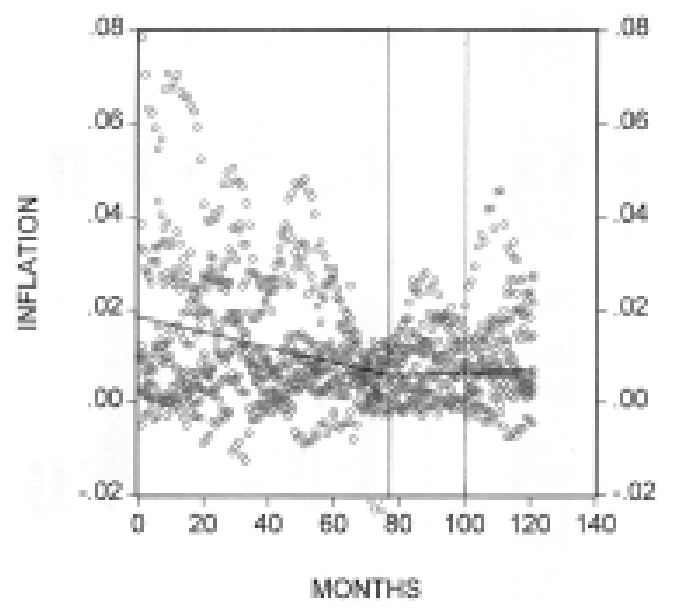

Finally we test the hypothesis that the transition between the regimes was smooth for the inflation rates. The separate 3-regime model is estimated as:

Before 98M1: Infl.differential

$$
\begin{aligned}
= & 1.973-0.017 * \text { Time } \\
& (0.000)(0.000)
\end{aligned}
$$

From 98M1 to 99M12: Infl.differential $=0.589+0.003 *$ Time

$$
\begin{aligned}
& (0.1915)(0.0970) \\
& =-0.696+0.016^{*} \text { Time } \\
& (0.1014)(0.0267)
\end{aligned}
$$

Figure 2. Inflation differential for a separate 3-regime regression for 11 EMU countries

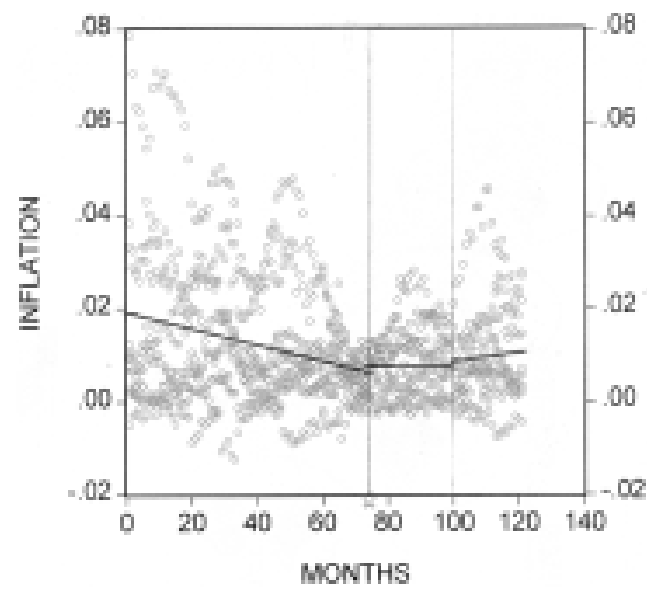


The estimates are rejecting the convergence hypothesis for the last regime and the 1.6 basis points divergence is significant. Moreover, note the divergence for the years 1998 and 1999. Indeed, the slope coefficient is significantly different from $0(\alpha=10 \%)$ and the F-test is significant as well ( $\mathrm{p}$-value $<.0001)$.

Concerning the third hypothesis about the number of regimes, we see a clear preference for the 3-regime model. (The AIC value for the 3-regime model is -5.884 while the AIC value for the 2-regime model is -4.660). Also the likelihood ratio test between the 2 models is highly significant. This means that all the convergence process happened in the Maastricht regime while the stabilisation process for the Amsterdam and the Euroland regime is quite different.

For the $4^{\text {th }}$ hypothesis about the smooth transition we find almost identical AIC and log-likelihood values for both models. Therefore we will prefer according to the principle of parsimony (i.e. the smallest number of parameters) the smooth transition model.

Conclusion 1: The convergence for the inflation rate in the EMU countries happened statistically significant during the Maastricht regime. For the $2^{\text {nd }}$ regime and the $3^{\text {rd }}$ regime we find a flat regression line (i.e. a levelling off) and the smooth transition model is supported by the data. From January 00 to September 01 we detect a small but non-significant divergence between the inflation rates.

\section{B. Long-term Interest Rates}

The 2-regime spline model for the 12 EMU members is estimated as:

Before 98M1: Int.differential $=2.990-0.048 *$ Time

(p-values)

(0.0000) (0.0000)

After 97M12: Int.differential $=1.500-0.015 *$ Time

(p-values)

(0.0000) (0.0015)

Thus, from April 1994 to December 1997, the monthly convergence was on average 4.8 basis points. The long-term interest rate differential - based on the mean of the three best performing countries - has on average decreased from $3 \%$ to $0.8 \%$ at the end of the first regime, 1997. There has been additional convergence for the second regime of 1.5 basis points with the differential decreasing to quite a low value: less than $0.2 \%$. The results are all significant at a $1 \%$ level (including the F-statistic). 
Figure 3. Convergence of the interest rate differential in the 2-regime spline model (of 12 EMU countries). The time series of Greece acts as an outlier. Note the bias of the trend in the second regime due to Greece.

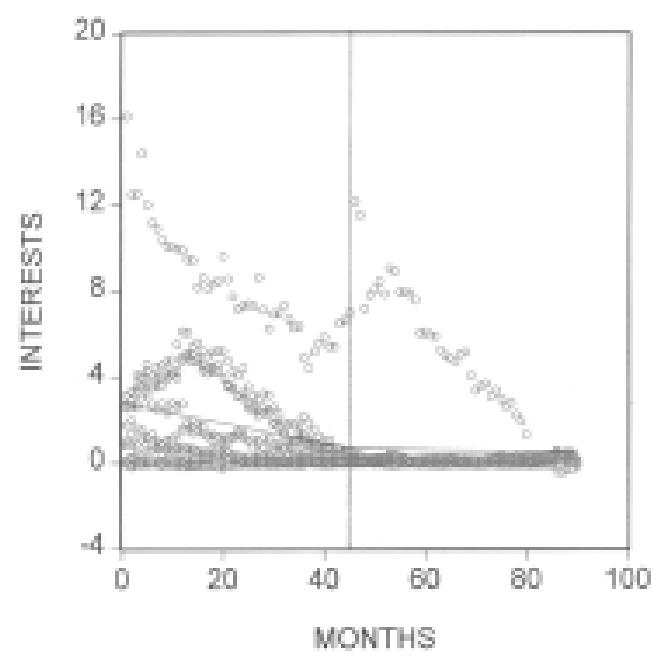

The spline estimate without Greece is:

Before 98M1: Int.differential $=2.200-0.045 *$ Time

(p-values)

(0.0000) (0.0000)

After 97M12: Int.differential $=0.220-0.001 *$ Time

(p-values)

(0.0000) (0.0000)

The 11 countries of Euroland show a good convergence trend ( 4.5 basis points per month) for the interest rates in the first regime. The convergence has stabilized over the last 2 regimes, and seemed to have been more constant than for the inflation rates. The estimated differential with respect to the 3 best performing countries is 2.2\% for April 1994, 0.2\% for December 1997 and about 0.15\% for September 2001. As only the latter value is similar to that of the regression with Greece, this shows the size of the distortion effect, although it is vanishing over time.

The 3-regime spline model (again without Greece) was estimated as:
Before 98M1: Int.differential $=2.177-0.043^{*}$ Time
(p-values)
(0.0000) (0.0000)

From 98M1 to 99M12: Int.differential $=0.535-0.007 *$ Time

(p-values)

(0.0000) (0.0000)

After 99M12: Int.differential $=-0.585+0.009 *$ Time

(p-values)

(0.0000) (0.2016) 
The slope coefficient is (statistically) significant in the second regime but not so for the $3^{\text {rd }}$ regime. Practically the convergence process for the interest rates has already been flat in the $2^{\text {nd }}$ regime and has stabilized in the $3^{\text {rd }}$ regime. Clearly, the variance reduction is impressive for the Maastricht regime, as we see from Figure 4.

The estimation for the separate 2-piece linear regression model without Greece is:

Before 98M1: Int.differential $=2.151-0.042 *$ Time

$$
\text { (0.0000) (0.0000) }
$$

From 98M1 to 99M12: Int.differential $=0.176-0.001 *$ Time

$$
\begin{aligned}
& (0.0005)(0.0001) \\
& =-0.519+0.009 * \text { Time } \\
& (0.0047)(0.0000)
\end{aligned}
$$

Now to the question: what model is preferred, the 2- or the 3-regime model? Like for the inflation rate model, we see a clear preference for the 3regime model. The AIC value for the 2-regime model is 2.888 while the AIC value for the 2regime model is 4.346 , and the likelihood ratio test is highly significant. (The difference of the log-likelihoods is about 150 which is distributed as a chi-square variable with 1 d.f., the difference of the numbers of parameters between model (2) and (5)). We find an impressive convergence process for the inflation rates during the Maastricht regime (see last section) that was matched by a similar

Figure 4. The 3-regime spline convergence model for interest rate differentials

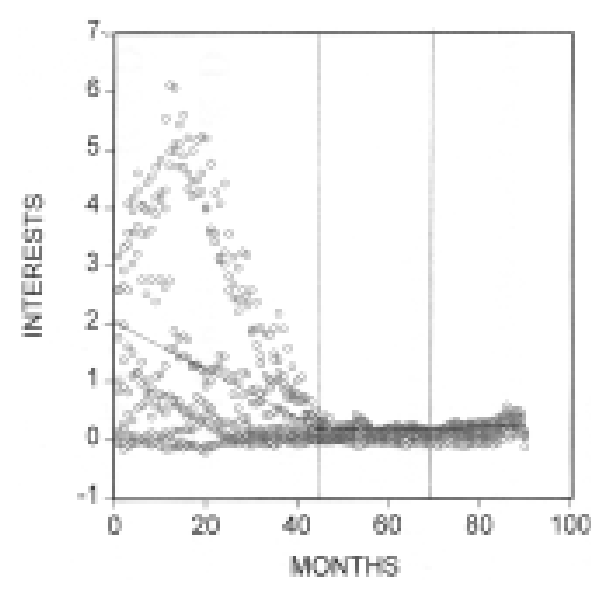


Figure 5. Separate regression for the interest rate differential (breaks points at 97M12 and 99M12) without Greece

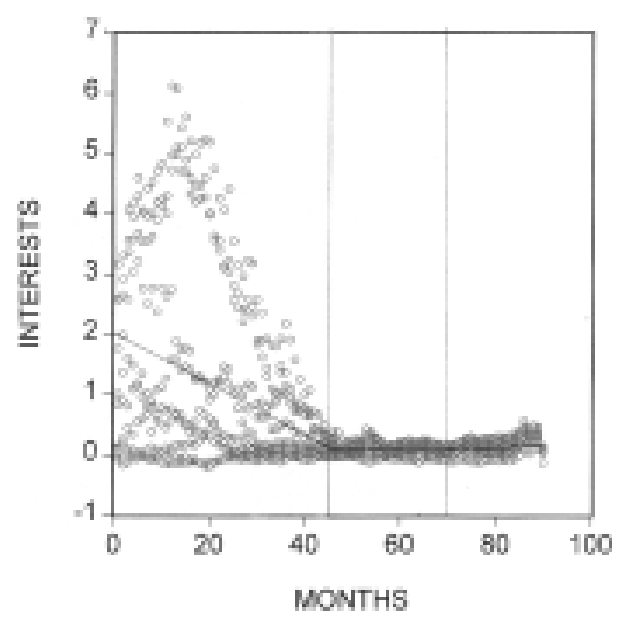

process for the interest rate differentials. Note that the stabilisation process for the Amsterdam and the Euroland regime is quite similar. While the slope of the $2^{\text {nd }}$ regime was slightly negative, it became positive in the $3^{\text {rd }}$ regime, although both slopes are non-significant. Concerning hypothesis 4 about the smooth transition we find again almost identical AIC and log-likelihood values for both models. (The AIC value is 2.892). Thus, we prefer the smooth transition model for the interest rates convergence.

Conclusion 2: The convergence for long-term interest rates in the EMU for the first two regimes was similar to the convergence process of the inflation rates and has levelled of in the last two regimes from January ' 98 to September '01. The smooth transition model is preferred by the data, and a slight divergence effect in mean and variances can be seen for the last regime

\section{Annual Public Deficit to GDP}

The analysis for the annual public deficit is based on annual data. This implies shorter time series and the estimation of a 2-regime model, i.e. we will mainly learn about the convergence process before and after 1997. Because of pooling the data, we have enough d.f. to estimate a 2-regime model, but these yearly estimates are less reliable and interpretable than quarterly results. The spline estimates are

Before 1998: Ann.Deficit $=5.31 \%-0.30 \% *$ Time

(p-values)

(0.000) (0.0303) 
After 1997: Ann.Deficit $=12.26 \%-1.17 \% *$ Time

(p-values) (0.000) (0.0134)

We see that the EMU countries reduced their annual deficits with an annual rate of $0.3 \%$-points ( $p$-value $=0.0303$ ). In the second regime the trend was even more evident $(-1.2 \%$ per year with a p-value of $1.3 \%)$. The estimated regression line crosses the 3\% target line in 1997.

2-regime regression estimates without Greece for the annual deficit:

Before 1998: Ann.Deficit $=4.35-0.21 *$ Time,

$$
\text { (0.000) (0.0994) }
$$

After 1997: Ann.Deficit $=11.52-1.10 *$ Time.

$$
\text { (0.000) (0.0063) }
$$

The slope in the first regime is flatter than before and is only significant at a $10 \%$ level. This means that the hypothesis for non-convergence during the Maastricht regime cannot be rejected. The estimated regression line again crosses the $3 \%$ line in 1997. In the second regime the negative trend is significant, irrespectably if Greece is included or not. This means that the EMU countries started seriously reducing their annual deficit only in the last regimes since 1997. The F-value is highly significant at a $.001 \%$ level. Note that the general trend has

Figure 6. Spline model of the annual deficit for the 11 EMU members

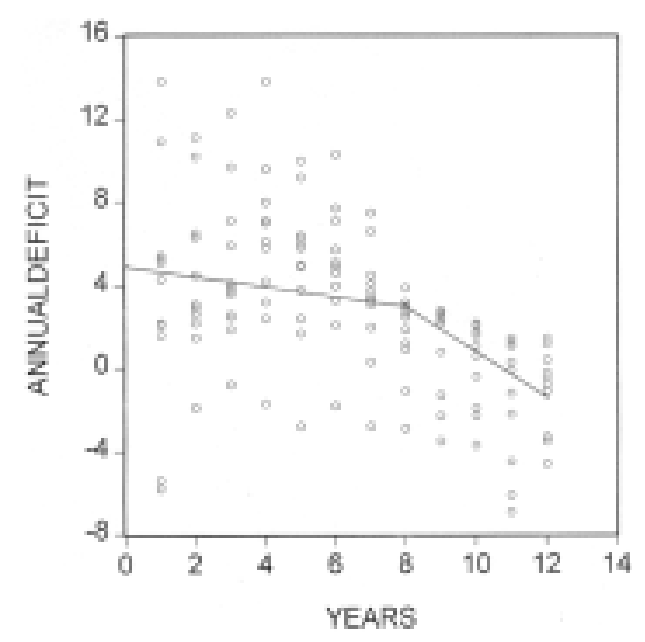


changed for most countries in the last regime, since all countries were still below the 3\% line for their projected annual deficit in 2001.

Conclusion 3: On average the EMU members have decreased their annual public deficit (ratio to GDP) over the whole period since 1992. Before 1997, in the Maastricht regime, the reduction of the deficit was not statistically significant and also no convergence in the variances can be seen. Since 1997 the time trend in the means is significant and the variance is smaller than in the Maastricht regime.

\section{Overall Public Debt Ratio to GDP}

Finally we test if EMU members have decreased the overall public debt ratio on average in 2000 to 2001 . The linear spline model including all the 12 members is estimated as:

Before 1998: Debt $=63.48+1.45^{*}$ Time

$$
\text { (0.000) (0.2815) }
$$

After 1997: Debt $=105.34-3.78 *$ Time

$$
\text { (0.000) (0.1315) }
$$

We see that convergence will not take place in the first regime: on the contrary, we see an increase of the overall public debt ratio for regime 1 , on average with an annual rate of $1.45 \%$. But this coefficient is not statistically significant (p-value $=0.2815$ ), and in the second regime the countries tend to decrease their debt levels by $3.8 \%$ per annum; but the slope coefficient is also not significant: $\mathrm{p}$-value $=$ $13.15 \%$. Since only 12 annual observations are available, this small number of observation can explain this low empirical evidence, i.e. leading to insignificant results. Interestingly, the estimated regression line reaches the $60 \%$ level at the end of our observation period in 2002.

The estimates of the 2-regime spline model for public debt (excluding Greece) are:

Before 1998: Debt $=61.86+1.20 *$ Time

$$
\text { (0.0000) (0.3891) }
$$

After 1997: Debt $=101.22-3.72 *$ Time

$$
\text { (0.0000) (0.1712) }
$$

All estimates and p-values do not change substantially from the previous regression including Greece and the fit has not improved.

In order to find a significant trend model we have excluded those countries, 
Figure 7. 2-regime spline model of the overall public debt ratio (12 EMU members)

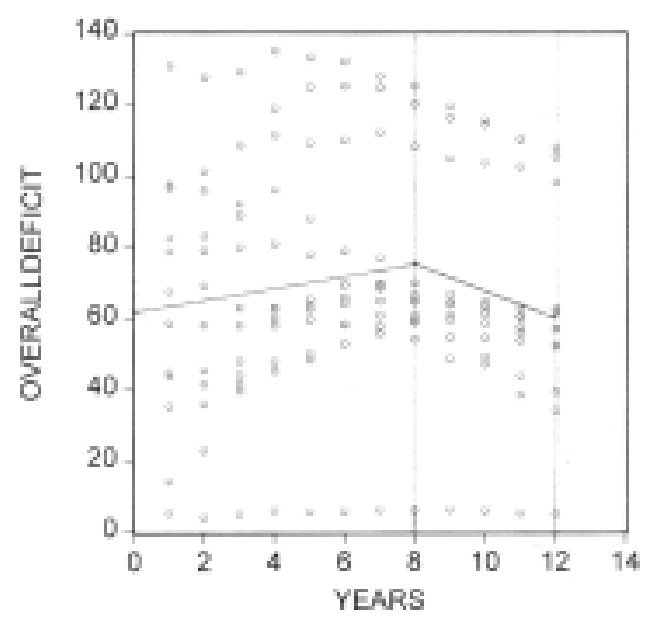

which might influence through extreme values the average behavior. Such a country is Luxembourg because of its low debt ratios (see Figure 8), and Belgium, Italy and Greece with high debt levels on the other side. Thus we estimate the aggregate convergence model for the remaining 8 middle countries:

Before 1998: Debt $=55.57+1.25 *$ Time (p-values) (0.000) (0.0770)

After 1997: Debt $=94.95-3.67 *$ Time (p-values) (0.000) (0.0076)

Figure 8. 2-regime model of the overall public debt for (11 EMU countries without Greece)

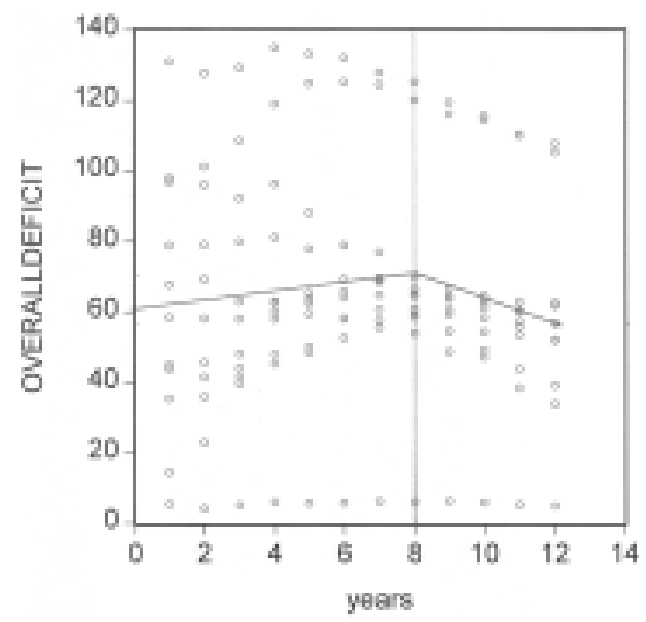


For these 8 countries the debt increases $1.25 \%$ annually (the p-value is $10 \%$ ) during the first regime until 1997, the F-test is significant. The estimated debt in 1997 is about $65.5 \%$, which is above the $60 \%$ ceiling target. The level was at $55.6 \%$ in 1990, therefore we see a divergence until 1997 but a significant debt decrease of $3.7 \%$ annually over the second regime. Therefore the estimated regression line for the 8 countries crosses the $60 \%$ line in 1999. This means that the 8 countries maintain the trend of reducing their annual deficit until 2002 with an estimated value of $50.9 \%$.

Conclusion 4: The convergence analysis for annual debts reveals the most heterogeneous behaviour: during the Amsterdam regime until 1997 the debt ratio was slightly but not significantly increasing for 8 "core" countries. Since 1997 the trend is significantly decreasing also for the remaining 4 countries. Overall, after a flat start during the Maastricht regime, a general trend of reducing national debts since 1998 can be observed, which continued in 2000 and 2001.

Additionally, the number of EMU members not meeting the $60 \%$ target on the overall public debt ratio has decreased in 2000 and 2001. Figure 10 shows a steadily decreasing number since 1996, particularly in 2000 and 2001. While there were 9 countries exceeding the $60 \%$ ceiling in 1996, only 7, 6 and 5 did so for 1999, 2000 and 2001 respectively. This is a sign for a small improvement of the debt ratio, but the evidence for a rigorous debt convergence remains weak since all countries are required to have a debt ratio lower than $60 \%$.

Figure 9. Overall public debt for the middle EMU members (without Belgium, Luxembourg, Greece and Italy)

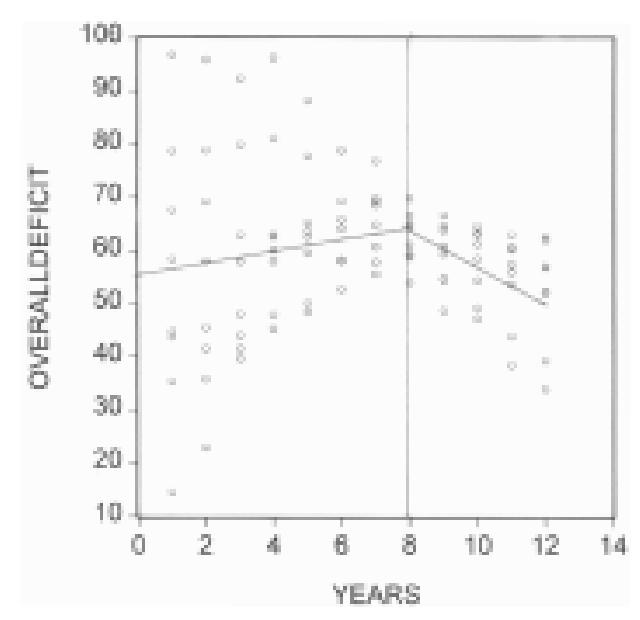


Figure 10. Number of countries with overall debt ratio above $60 \%$

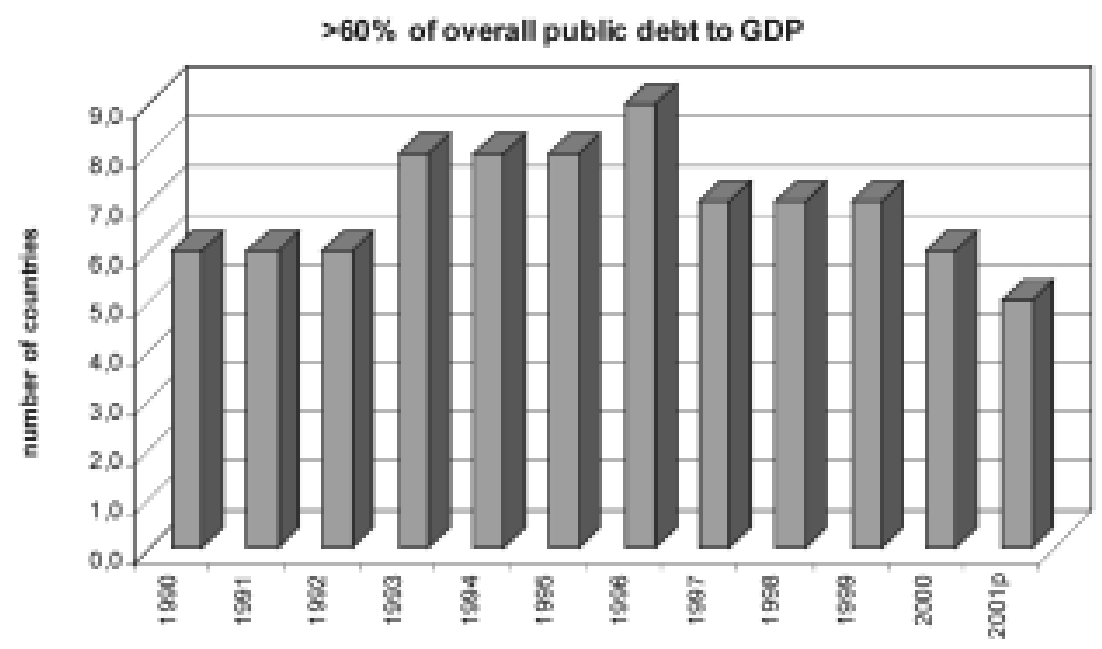

\section{Is There Convergence in the $2^{\text {nd }}$ Moments?}

We are interested if additionally to the convergence process in the mean equation $\left(1^{\text {st }}\right.$ moments $)$ we can find a convergence process in the variance equations.

As expected from the scatterplots, also the residual variances of the convergence models are decreasing functions of time. This is seen from the following estimations of the spline or the separate piecewise regression model with heteroskedastic errors (the appendix discusses the specification of these models).

(a) Interest rates: The variance equation of the continuous spline model for the interest rates is given by

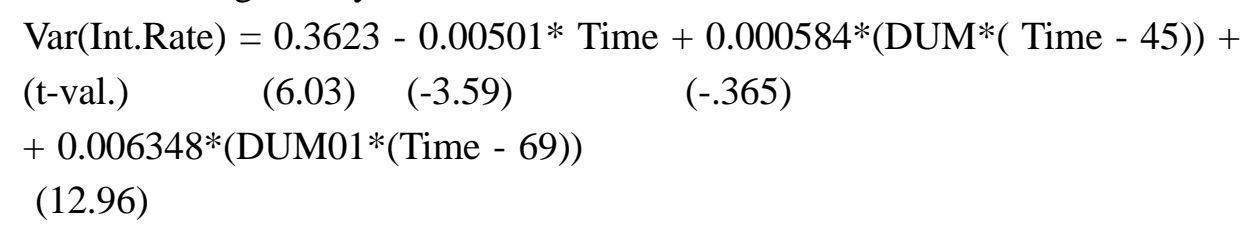

The log-likelihood is $-243.322(\mathrm{AIC}=.563)$ is much higher than the model without the variance equation with log-likelihood -1295.541 and AIC = 2.888). For the separate 3-regime model we have -397.40 and AIC $=.914$, so we see a clear preference for the spline model.

(b) Inflation rates: The variance equation of the smooth (spline) model for the 
inflation rates is given by the monthly equation

$\operatorname{Var}($ inflation $)=1 * \mathrm{e}-05-7.32 \mathrm{e}-08 *$ Time $+3.83 \mathrm{e}-08 *(\mathrm{DUM} *($ Time -76$))-1.24 \mathrm{e}-07 *$

(t-val.) (4.15) (-1.91) (.38)

(DUM01*(Time -100))

The log-likelihood is 4214.45 (AIC $=-6.96$ ) and is much higher than the model without the variance equation having a log-likelihood 3561.1 and $\mathrm{AIC}=-5.867$. In contrast, for the separate 3-regime model we find a log-likelihood 4163.35 (AIC $=-6.86)$ and with ARCH: $3561.4(\mathrm{AIC}=-5.88)$, so we see a clear preference for the heteroskedastic spline model.

(c) Public debt: The variance equation for the debt ratio was estimated as:

$\operatorname{Var}($ debt $)=295.96-28.84 *$ YEARS + 20.07*DUM9899-3.79* (DUM9899*YEARS) $-118.9 *$ DUM01-15.05*(DUM01*YEARS)

Only the YEARS coefficient is statistically significant with a t value of -2.5 . The log-likelihood is $-387.75(\mathrm{AIC}=8.161)$ is much higher than the model without the variance equation with log-likelihood -343.09 and $\mathrm{AIC}=7.356$. For the separate 2-regime model we have $-387.6(\mathrm{AIC}=8.200)$ and the model with an ARCH component yields: -346.64 (AIC $=7.51$ ), so we see clear preference for the spline model.

(d) Annual deficit: Summary of the heteroskedastic model

The log-likelihood is -319.48 ( $\mathrm{AIC}=4.55$ ) and is much higher than the model without the variance equation with log-likelihood -374.43 (AIC $=5.24)$. For the separate 3-regime model we find a log-likelihood of -373.13 (AIC $=5.27)$; with an additional variance equation the log-likelihood increases to -321.13 ( $\mathrm{AIC}=4.65$ ), so we see clear preference for the spline model.

Note: No coefficient of the variance equation is significant for the separate 2regime regression (therefore it is not shown) while only the YEARS coefficient is significant for the spline model.

(e) Regression diagnostics: How sensitive are the regimes?

Also we have made a simple analysis concerning the break points of our 2 or 3regime model with and without heteroskedastic errors. As it turns out, there is no big difference between the log-likelihood values or the AIC values if the breakpoint is allowed to change over a period of +-3 months from the endpoints of the regimes. We conclude that the choice of the break points does not alter our results. 
Table 1. Sensitivity with respect to the break point for inflation rates Simple spline model and heteroskedastic spline model

\begin{tabular}{ccccc}
\hline $\mathrm{t}$ & log-lik. & AIC & Het. log-lik. & AIC \\
\hline $76:$ & 3104.118, & -4.65983 & 3848.860 & -5.772892 \\
$74:$ & 3104.183, & -4.65993 & 3836.404 & -5.754176 \\
$72:$ & 3104.198 & -4.65995 & 3822.859 & -5.733823 \\
$70:$ & 3104.169 & -4.660 & 3809.586 & -5.713879 \\
\hline
\end{tabular}

\section{Conclusions}

The paper analysed the convergence process of the 4 Maastricht variables over the last 12 years and found 3 rather different regimes since the EMU was established in 1992. While the interest rates and the inflation rates converged until 1997, the annual deficit and the public debt started declining after 1997. Also the variance between the EMU countries, a measure for heterogeneity, decreased parallel to the level processes. Our findings can be summarized as follows:

(1) The target-oriented convergence for the inflation rate of the EMU countries all happened in the Maastricht regime. During the $2^{\text {nd }}$ regime and $3^{\text {rd }}$ regime the time series stay within the bounds of the target path. The convergence processes has remained on a constant level but the variance of the path has slightly increased in the last regime. Over the whole period the spline model is supported; in the $3^{\text {rd }}$ regime from January ' 00 to September ' 01 there is a small tendency for divergence.

(2) The convergence for long-term interest rates in the EMU was impressively strong for the first regime and stabilized around the target path for the next two regimes. Interestingly, we find a statistical significant divergence for the last regime from Jan. 2000 to Sept. 2001, but the amount is rather small at the moment.

(3) During the first (Maastricht) regime the budget discipline in terms of the annual deficit was rather weak, which can be seen from the non-significant but negative trend. This shows that the EMU countries failed to achieve a targeted convergence during the Maastricht regime. But over the second and third regime since 1999, on average, the EMU members have decreased their annual public deficit to GDP dramatically, but the trend has not yet levelled off. The conver-gence process of the annual deficit is different with respect to two points. First it is characterized only by a convergence of the mean process in $2^{\text {nd }}$ and $3^{\text {rd }}$ regime, the while convergence in the second moments has taken place (over the whole period).

(4) The behaviour of the debt ratios among the EMU countries is rather hetero- 
geneous. A majority of 8 EMU countries exhibit a clear decreasing debt-ratio for the last two regimes. This trend is shared with the remaining EMU countries for the last two regimes but on different levels. While Luxembourg had always been below the $60 \%$ target line, 3 countries of the EMU are still not meeting this threshold. Moreover, we observe a targeted positive but not significant trend for the debt-ratio over the first regime. The variance of the target path has decreased over the first regime but not over the $2^{\text {nd }}$ and $3^{\text {rd }}$ regime

(5) In general, the spline model is supported by the convergence process that indicates a "soft landing" of the convergence process at the target levels for inflation and interest rates. The model estimates do not show a soft landing for the government debt and deficit variables. Compared to the 2-regime model, the 3regime regression model gives a better fit and the likelihood ratio test between the models is significant.

(6) The smooth heteroskedastic convergence model, i.e., the regression model which aims at first and second moment convergence, is supported by the data for all 4 Maastricht criteria. For the ARCH equation, the most important coefficient is the negative coefficient of the time variable, for all time series. This shows that the convergence process in the first moments (the mean equation) was accompanied by an additional and also significant convergence process in the second moments (the variance equation).

(7) Model diagnostics: The pooled cross-sectional convergence model in the present form does not allow estimating autoregressive models. Only in a more complex model where the time series are modelled independently, the potential autocorrelation can be removed from the model estimation.

Overall we see that the convergence process follows the economic expectations: Interest rates are following a more tighter convergence path than inflation rates, because of the market pressures of a common currency and both are under the control of monetary authorities, while deficit variables are by nature more volatile and their convergence paths have more freedom to deviate from a target.

\section{Acknowledgement}

We thank Marco Delvai and Stefano Raffaelli for computing assistance. We also thank two anonymous referees for the critical and valuable remarks.

Recevied 30 May 2002, Accepted 21 March 2003 


\section{References}

Akaike H. (1973) Maximum likelihood estimation of Gaussian autoregressive moving average models; Biometrika 60, 255-265.

Barro Robert J. and Xavier X. Sala-I-Martin (1995), “Economic Growth”, McGraw-Hill, New York.

Ben-David Dan (1993), "Equalizing Exchange: Trade Liberalization and Income Convergence", Quarterly Journal of Economics (November), 653-679.

Dornbusch, R. (1976), "Expectations and exchange rate dynamics", Journal of Political Economy, 84, 1161-1176

European Monetary Union (1996), "Pact of Stability and Growth", http://europa.eu.int/ scadplus/leg/en/lvb/125021.htm

European Monetary Union (1992), “Convergence Criteria”, EC Treaty, Article 109j(1).

Treaty on EU (1999), Title VII (ex VI) Economic and Monetary Policy, Chapter 2 Monetary Policy, Articles 105(ex 105)-124(ex 109m), in: European Union, book 1. http://europa.eu.int/eur-lex/en/treaties/dat/treaties_en.pdf

Hobijn B. and Franses P.H. (2000), "Asymptotically Perfect Convergence of Productivity", Journal of Applied Econometrics 15, 59-81.

Hobijn B. and Franses P.H. (2001), “Are living standards converging?”, Structural Change and Economic Dynamics 12, 171-200.

Pindyck and Rubinfeld (1998), "Econometric Models and Economic Forecasting", $4^{\text {th }}$ edition, McGraw-Hill.

Popper K. (2000), “Conjectures and Refutations: the growth of scientific knowledge”, $5^{\text {th }}$ edition, Routledge, London and New York.

Quah Danny T. (1993), "Empirical Cross-section Dynamics in Economic Growth", Working Paper (December), London School of Economics

Quah Danny T. (1997), "Empirics for Growth and Distribution: Stratification, Polarization and Convergence Clubs”, Journal of Economic Growth (March), 27-59.

\section{Appendix: Heteroskedastic Convergence Models}

For modelling the convergence of variances (convergence "in variance") it is possible to re-parameterize the variances by a linear function of exogenous regressors.

a) The heteroskedastic 2-regime spline model is given by a mean and variance equation:

$$
\mathrm{y}_{\mathrm{t}}=\mathrm{a}_{0}+\mathrm{a}_{1} \mathrm{x}_{\mathrm{t}}+\mathrm{b}_{1}\left(\mathrm{x}_{\mathrm{t}}-\mathrm{x}^{*}\right) \mathrm{D}_{\mathrm{t}}+\mathrm{u}_{\mathrm{t}},
$$

$\operatorname{Var}\left(\mathrm{u}_{\mathrm{t}}\right)=\mathrm{s}_{\mathrm{t}}^{2}=\alpha_{0}+\alpha_{1} \mathrm{x}_{\mathrm{t}}+\beta_{1}\left(\mathrm{x}_{\mathrm{t}}-\mathrm{x}^{*}\right) \mathrm{D}_{\mathrm{t}}$,

with the dummy variable $D_{t}$. This leads to the following variance equations of 
heteroskedastic regression model:

$$
\begin{array}{lll}
D_{t}=0: & s^{2}=\alpha_{0}+\alpha_{1} x_{t} & \text { for } x_{t}<x^{*}, \\
D_{t}=1: & s^{2}{ }_{t}=\beta_{0} *+\beta_{1} * x_{t}, & \text { for } x_{t}>x^{*} .
\end{array}
$$

The coefficients for regime 2 are $\beta_{0}^{*}=\alpha_{0}-\beta_{1} x^{*}$ and $\beta_{1}^{*}=\alpha_{1}+\beta_{1}$.

b) The separate 2-regime heteroskedastic regression model is specified with a "multiplicative dummy" variable $\mathrm{D}_{t}$

$$
\begin{aligned}
& \mathrm{y}_{\mathrm{t}}=\mathrm{a}_{0}+\mathrm{a}_{1}\left(\mathrm{x}_{\mathrm{t}}-\mathrm{x}^{*}\right)+\mathrm{b}_{0} \mathrm{D}_{\mathrm{t}}+\mathrm{b}_{1}\left(\mathrm{x}_{\mathrm{t}}-\mathrm{x}^{*}\right) \mathrm{D}_{\mathrm{t}}+\mathrm{u}_{\mathrm{t}}, \\
& \mathrm{s}^{2}=\alpha_{0}+\alpha_{1}\left(\mathrm{x}_{\mathrm{t}}-\mathrm{x}^{*}\right)+\beta{ }_{0} \mathrm{D}_{\mathrm{t}}+\beta_{1}\left(\mathrm{x}_{\mathrm{t}}-\mathrm{x}^{*}\right) \mathrm{D}_{\mathrm{t}} .
\end{aligned}
$$

c) The separate 3-regime heteroskedastic regression model has the following mean and variance equation:

$$
\begin{aligned}
& \mathrm{y}_{\mathrm{t}}=\mathrm{a}_{0}+\mathrm{a}_{1}\left(\mathrm{x}_{\mathrm{t}}-\mathrm{x}_{\mathrm{a}}{ }^{*}\right)+\mathrm{b}_{0} \mathrm{D}_{\mathrm{t}}^{\mathrm{a}}+\mathrm{b}_{1}\left(\mathrm{x}_{\mathrm{t}}-\mathrm{x}_{\mathrm{a}}{ }^{*}\right) \mathrm{D}_{\mathrm{t}}^{\mathrm{a}}+\mathrm{c}_{0} \mathrm{D}_{\mathrm{t}}^{\mathrm{c}}+\mathrm{c}_{1}\left(\mathrm{x}_{\mathrm{t}}-\mathrm{x}_{\mathrm{c}}{ }^{*}\right) \mathrm{D}_{\mathrm{t}}^{\mathrm{c}}+\mathrm{u}_{\mathrm{t}}, \\
& \operatorname{Var}\left(\mathrm{u}_{\mathrm{t}}\right)=\mathrm{s}_{\mathrm{t}}^{2}=\alpha_{0}+\alpha_{1}\left(\mathrm{x}_{\mathrm{t}}-\mathrm{x}_{\mathrm{a}}{ }^{*}\right)+\beta_{0} \mathrm{D}_{\mathrm{t}}^{\mathrm{a}}+\beta_{1}\left(\mathrm{x}_{\mathrm{t}}-\mathrm{x}_{\mathrm{a}}{ }^{*}\right) \mathrm{D}_{\mathrm{t}}^{\mathrm{a}}+\gamma_{0} \mathrm{D}_{\mathrm{t}}^{\mathrm{c}}+\gamma_{1}\left(\mathrm{x}_{\mathrm{t}}-\right. \\
& \left.\mathrm{x}_{\mathrm{c}}{ }^{*}\right) \mathrm{D}_{\mathrm{t}}^{\mathrm{c}}
\end{aligned}
$$

where $\mathrm{D}^{\mathrm{a}}{ }_{\mathrm{t}}$ and $\mathrm{D}^{\mathrm{c}}{ }_{\mathrm{t}}$ are the dummy variables for the regimes $\mathrm{A}$ and $\mathrm{B}$, respectively.

d) Finally, the heteroskedastic 3-regime spline model has the form:

$$
\begin{gathered}
\mathrm{y}_{\mathrm{t}}=\mathrm{a}_{0}+\mathrm{a}_{1}\left(\mathrm{x}_{\mathrm{t}}-\mathrm{x}_{\mathrm{a}}{ }^{*}\right)+\mathrm{b}_{1}\left(\mathrm{x}_{\mathrm{t}}-\mathrm{x}_{\mathrm{a}}{ }^{*}\right) \mathrm{D}_{\mathrm{t}}^{\mathrm{a}}+\mathrm{c}_{1}\left(\mathrm{x}_{\mathrm{t}}-\mathrm{x}_{\mathrm{c}}{ }^{*}\right) \mathrm{D}_{\mathrm{t}}^{\mathrm{c}}+\mathrm{u}_{\mathrm{t}}, \\
\operatorname{Var}\left(\mathrm{u}_{\mathrm{t}}\right)=\mathrm{s}_{\mathrm{t}}^{2}=\alpha_{0}+\alpha_{1}\left(\mathrm{x}_{\mathrm{t}}-\mathrm{x}_{\mathrm{a}}{ }^{2}\right)+\beta_{1}\left(\mathrm{x}_{\mathrm{t}}-\mathrm{x}_{\mathrm{a}}{ }^{*}\right) \mathrm{D}_{\mathrm{t}}^{\mathrm{a}}+\gamma_{1}\left(\mathrm{x}_{\mathrm{t}}-\mathrm{x}_{\mathrm{c}}{ }^{*}\right) \mathrm{D}_{\mathrm{t}}^{\mathrm{c}} .
\end{gathered}
$$

The heteroskedastic regimes are given as

$$
\begin{aligned}
& 1^{\text {st }} \text { regime, } \mathrm{D}_{\mathrm{t}}^{\mathrm{a}}=0: \quad \mathrm{s}_{\mathrm{t}}{ }^{2}=\alpha_{0}+\alpha_{1}\left(\mathrm{x}_{\mathrm{t}}-\mathrm{x}_{\mathrm{a}}{ }^{*}\right) ; \\
& 2^{\text {nd }} \text { regime, } \mathrm{D}_{\mathrm{t}}^{\mathrm{a}}=1: \quad \mathrm{s}_{\mathrm{t}}{ }^{2} \alpha_{0}+\beta_{0}+\left(\alpha_{1}+\beta_{1}\right)\left(\mathrm{x}_{\mathrm{t}}-\mathrm{x}_{\mathrm{a}}{ }^{*}\right) ; \\
& 3^{\text {rd }} \text { regime, } \mathrm{D}_{\mathrm{t}}^{\mathrm{a}}=1 \text { and } \mathrm{D}_{\mathrm{t}}^{\mathrm{c}}=1: \\
& \mathrm{s}_{\mathrm{t}}^{2}=\alpha_{0}+\beta_{0}+\gamma_{0}+\left(\alpha_{1}+\beta_{1}+\gamma_{1}\right)\left(\mathrm{x}_{\mathrm{t}}-\mathrm{x}_{\mathrm{c}}{ }^{*}\right)+\gamma_{1}\left(\mathrm{x}_{\mathrm{a}}{ }^{*}-\mathrm{x}_{\mathrm{c}}{ }^{*}\right) .
\end{aligned}
$$

